\title{
Un modelo estructural del auto-concepto, la motivación autónoma y el rendimiento académico en perspectiva transcultural ${ }^{1}$
}

\author{
Wondimu Ahmed ${ }^{1}$ y Marjon Bruinsma ${ }^{2}$
}

${ }^{1}$ Instituto de Investigación Educativa, Universidad de Groningen
${ }^{2}$ Centro para la Docencia y el Aprendizaje, Universidad de Groningen

Holanda

w.ahmed@rug.nl

\footnotetext{
${ }^{1}$ Este artículo se basa en una tesis de Master que la presentó Wondimu Ahmed a la Universidad de Groningen, bajo la supervision del Dr Marjon Bruinsma. Wondimu Ahmed actualmente es estudiante de doctorado en esta Universidad.
} 


\section{Resumen}

El propósito de este trabajo era proponer y comprobar un modelo motivacional del rendimiento, integrando constructos de las teorías de auto-concepto y de la autodeterminación, y explorar diferencias de grupos culturales en este modelo. Para ello, se recogieron medidas de auto-informe sobre la autoestima global, el auto-concepto académico, la motivación académica y el rendimiento académico para estudiantes posgraduados asiáticos y europeos. El análisis consistió en modelos de equación estructural para la muestra general $(\mathrm{N}=181)$ y para los distintos grupos culturales (asiático $=94$ y europeo $=87$ ). Para la muestra general, el modelo propuesto sí se ajustó a los datos de manera razonable, con todas las propuestas coeficientes de dependencia siendo estadísticamente significativas. En los análisis de los grupos culturales por separado, aunque el modelo se ajustó a los datos de ambas muestras, una de las coeficientes de dependencia no era significativa en la sub-muestra asiática. Se discuten los resultados a la luz de las teorías de auto-concepto y auto-determinación, así como la perspectiva de diferencias culturales.

Palabras clave: auto-concepto académico, teoría de la auto-determinación, autoestima, motivación autónoma, rendimiento académico, diferencias culturales 